\title{
Compounded Vulnerability: The Consequences of Immigration Detention for Institutional Attachment and System Avoidance in Mixed-Immigration-Status Families
}

\author{
Caitlin Patler, University of California, Davis ${ }^{1}$ \\ Gabriela Gonzalez, University of California, Irvine \\ ** This article has been accepted for publication in Social Problems, \\ published by Oxford University Press. **
}

\begin{abstract}
While an extensive body of literature has analyzed the spillover and intergenerational consequences of mass incarceration, fewer studies explore the consequences of a parallel system: mass immigration detention. Every year, Immigration and Customs Enforcement imprisons hundreds of thousands of noncitizens as they await adjudication on their deportation proceedings, sometimes for months or years at a time. Many detained individuals have lived in the United States for decades and have spouses and/or dependent children that rely on them. This analysis brings together research on immigrant families, mass incarceration, and system avoidance to examine the spillover consequences of immigration detention. Using a multigenerational and multi-perspective research design, we analyze 104 interviews conducted in California with detained parents, non-detained spouses/partners, and their school-age children. Findings suggest that members of these mixed-status families may limit their engagement with surveilling institutions during a family member's detention. These experiences are rooted in what we call compounded vulnerability - that is, both in the experience of parental/spousal confinement but also in their positionality as members of mixed-immigration-status families facing the possibility of deportation.
\end{abstract}

KEY WORDS

Immigration detention, mixed-status families, system avoidance, parental incarceration, compounded vulnerability

\footnotetext{
${ }^{1}$ Please direct all correspondence to Caitlin Patler: patler@ucdavis.edu
}

\section{Acknowledgements}

We are grateful to Susan Coutin and Anna Haskins for their helpful comments on earlier drafts of the manuscript. Data used in this study from detained parents were collected in collaboration with Emily Ryo. This work was supported by the Russell Sage Foundation [93-16-15 to CP; any opinions expressed are those of the author(s) alone and should not be construed as representing the opinions of the Foundation]; UC Davis Humanities Institute Faculty Research Fellowship [to CP]; UCLA Institute for Research on Labor and Employment [to CP]; University of CaliforniaMexico Initiative [to CP]; and University of California Presidential Postdoctoral Fellowship Program [to CP]. 


\section{INTRODUCTION}

Between 2011 and 2013 alone, half a million U.S. citizen children experienced the apprehension, detention, and deportation of at least one parent (Capps et al. 2015). Every year, Immigration and Customs Enforcement (ICE) imprisons hundreds of thousands of noncitizens as they await adjudication on their deportation proceedings, sometimes for months or years at a time. However, relatively few studies have examined the impacts of immigration detention on mixed-immigration-status (or mixed-status) ${ }^{1}$ families (Brabeck and Xu 2010; Zayas et al. 2016; Golash-Boza 2019). ${ }^{2}$ In contrast, there is a robust literature on mass incarceration under criminal law. This body of work documents a host of deleterious consequences of incarceration that spill over onto families and impact economic wellbeing, housing, family relationships, and educational and health outcomes (for reviews see Wakefield and Wildeman 2013; Travis, Western, and Redburn 2014; Foster and Hagan 2015). Yet, the literature on the social consequences of incarceration has not fully theorized or explored outcomes for the family members of noncitizens who are detained by immigration authorities. This study aims to begin to fill these gaps by analyzing the spillover consequences of immigration detention.

We focus on whether family members express system avoidance behaviors following the detention of a loved one by immigration authorities. System avoidance generally refers to "the practice of individuals avoiding institutions that keep formal records (i.e. put them 'in the system') and therefore heighten the risk of surveillance and apprehension by legal authorities" (Brayne 2014: 368). Research suggests that individuals who have had direct contact with the criminal justice system go to great lengths to avoid surveilling institutions including the justice system, medical institutions, labor market institutions, and even educational institutions (Brayne 2014; Haskins \& Jacobsen 2017). However, the literature on system avoidance is limited in three 
ways. First, it has not fully tested the mechanisms of system avoidance behaviors. Second, there is inconclusive evidence about whether system avoidance spills over onto adult significant others of those with criminal justice system contact (Haskins \& Jacobsen 2017). Third, there is very little empirical work on the question of whether system/institutional avoidance may also be intergenerational.

We address these questions - of mechanisms, and spillover and intergenerational impacts of detention — by bridging the literatures on system avoidance and immigrant families. It is well known that immigrants with vulnerable legal statuses — especially undocumented immigrantsare wary of surveilling institutions given concerns about detection and deportation. Research has documented system avoidance behaviors among undocumented immigrant adults and undocumented children (Nuñez \& Heyman 2007; Menjívar and Abrego 2012; Jefferies 2014; Patler 2018a). There is also evidence that deportation fear spills over onto U.S. citizen children and other family members of undocumented immigrants (Dreby 2015, Enriquez 2015, Lopez 2019). Less clear is whether and how parental detention may trigger or exacerbate system avoidance behaviors among the spouses and children of immigrants in mixed-status families who may themselves be U.S. citizens or documented immigrants. We analyze these questions herein.

This study draws from a unique set of 104 multigenerational and multi-perspective indepth interviews conducted in California with three distinct groups of individuals impacted by immigration detention: detained parents, their non-detained spouses/partners with whom they share children, and those children. We use these interviews to explore adults' and children's attachment to institutions during and in the aftermath of a loved one's detention. Our findings suggest that both non-detained spouses and children of detained immigrants limit their engagement with certain institutions following the detention of their loved one. For example, 
prior to detention, the spouses in our study often had regular contact with records-keeping institutions such as social services agencies, hospitals and clinics, and their children's schools. After the detention of a spouse, many non-detained spouses began to avoid—or further avoidinteraction with the criminal justice system, as well as accessing much needed housing and food assistance and medical care. The children in our study — the majority of whom are U.S. citizens - were most commonly in contact with educational institutions prior to their parent's detention. After detention, most children altered the scope of their engagement with school and purposefully avoided seeking school-based academic and psychological support. Children also experienced feelings of distrust, betrayal, and disillusionment in the U.S. legal system that shifted their daily routines and aspirations for the future. In contrast, most families continue their involvement with religious organizations and the labor market.

We argue that the system avoidance behaviors of family members of detained immigrants are rooted in compounded vulnerability. Compounded vulnerability refers to the experiences of children and adults who are subject to the disadvantages of having a parent or spouse behind bars, while simultaneously being part of mixed-status families. In many mixed-status families, loved ones are vulnerable the uncertainties of the immigration legal process which can lead to permanent family separation via deportation of the detained individual, as well as to the potential for deportation even among those who are not detained, but may also have legally vulnerable immigration statuses. Our results provide evidence of spillover and intergenerational system avoidance and mistrust among spouses and children of detained immigrants that is rooted in compounded vulnerability. These findings are especially relevant in the current political context in which immigration laws are becoming increasingly punitive and mandatory and indefinite immigration detention ever more commonplace. ${ }^{3}$ Our study suggests that immigrant households 
and communities may be more severely and extensively disadvantaged by U.S. immigration detention than previously understood.

\section{THEORETICAL, EMPIRICAL, AND LEGAL BACKGROUND}

\section{System avoidance and mistrust}

Individuals who have been stopped by police, arrested, convicted, or incarcerated are less likely to interact with records-keeping institutions including hospitals, banks, workplaces, and even schools, compared to people without criminal justice system contact (Brayne 2014). The theorized goal of system avoidance behavior is to avoid re-apprehension and re-imprisonment. Previously incarcerated individuals may go out of their way to avoid further interaction with the justice system, even when doing so could help them - for example, calling the police after one is robbed or accessing services such as much-needed medical care-for which they or others are eligible (Goffman 2009). In contrast, criminal justice system contact has not been linked to decreased participation in religious organizations, suggesting that these institutions may not be perceived as potential ports of state surveillance (Brayne 2014).

Schools are records-keeping institutions that entire families interact with and may therefore become sites of system avoidance following justice system contact. Haskins and Jacobsen show that fathers with histories of incarceration are less involved in their children's schools and school-based activities, relative to those fathers without histories of incarceration (Haskins and Jacobsen 2017). Haskins and Jacobsen also examine whether mothers who are partners or former partners of individuals with histories of incarceration change their behavior vis-à-vis schools, but find inconclusive evidence of spillover system avoidance. The question of whether children engage in system avoidance as a result of parental confinement also remains 
unanswered. Understanding the answers to these questions is critical given the key role that educational institutions play in shaping life chances and mobility.

As another legally vulnerable community, noncitizens - especially those who are undocumented or hold "liminally legal” (Menjívar 2006) statuses — also avoid surveilling institutions. An established body of migration research documents the avoidance of surveilling institutions and the "chilling effects" of heightened immigration law enforcement. Immigrants are often fearful of interacting with government institutions: for instance, parents detained by immigration authorities receive fewer visits from undocumented children than parents of U.S. citizens, likely due to undocumented family's fears of "entering the belly of the beast" (Patler and Branic 2017: 24). Latino immigrants are less likely to report crimes than U.S.-born Latinos (Menjívar et al. 2018) and undocumented immigrants change their daily routines - e.g. taking different driving routes — to avoid interactions with law enforcement (Núñez and Heyman 2007). There is also evidence that U.S.-citizen members of mixed-status families engage in system avoidance behavior even though they are not directly eligible for detention or deportation: Research has documented reductions in qualified Medicaid enrollment, healthcare-seeking, and accessing service-providing institutions among U.S. citizens who may share households with noncitizens (Pedraza, Cruz Nichols and LeBrón 2017; Watson 2014). We hypothesize that the detention of a family member could instigate or exacerbate such system avoidance behaviors, given concerns about legal vulnerability (of both detained individuals and others) in mixed-status families.

\section{The Spillover Consequences of Imprisonment}


Compounded vulnerability describes the experience of having a confined parent or spouse while also being subject to the uncertainties of the immigration legal processes that can ultimately result in deportation and permanent family separation. We begin by explaining the first component of compounded vulnerability — the imprisonment of a family member-and how that could lead to system avoidance. To do so, we draw from literature on the collateral consequences of incarceration under criminal law. Many families experience substantial upheaval after a loved one is incarcerated, leading to significant collateral and intergenerational consequences (e.g. Hagan and Foster 2012; Wakefield and Wildeman 2013; Turney 2014; Turney and Haskins 2014; Wildeman and Turney 2014; Foster and Hagan 2015). The incarceration of a partner/spouse can yield a loss of material resources (e.g., food, clothing, transportation, housing) that threaten economic survival during incarceration; expenses related to confinement (e.g., visitation, phone calls, commissary, legal costs) increase these demands. Spousal incarceration can lead to periods of homelessness, food insecurity, and emotional instability for non-incarcerated spouses and their children (Turney 2011; Wildeman 2014; Turney 2015). Mothers who share children with men behind bars may also experience declines in mental and physical health (Fishman 1988a, Girshick 1996, Braman 2004; Wildeman, Lee and Comfort 2013). It is reasonable to expect that when faced with such challenges, system-impacted individuals and their family members might do everything in their power to avoid having to go through these experiences again. System avoidance may be one of those strategies.

For children, parental incarceration also poses significant threats to educational success and institutional attachment. When a parent is incarcerated under criminal law, children are more likely to experience academic failure, special education placement, and grade retention as compared to their peers without incarcerated parents (Haskins 2014; Turney and Haskins 2014; 
Haskins et al. 2018). In addition, children with an incarcerated parent can suffer from teacher stigma as educators rank children of the incarcerated as less competent and with more behavioral problems than the other students (Dallaire et al., 2010; Wildeman et al. 2017). Children may also suffer stigma from their peers and be the targets of teasing or bullying when the nature of their parent's absence is discovered (Boswell and Wedge 2002). It is possible that such experiences could leave children less trusting of educational institutions and therefore more likely to engage in system avoidance behaviors.

\section{Immigration Detention, Compounded Vulnerability, and System Avoidance}

The vulnerability of families dealing with the imprisonment of a loved one may be compounded in mixed-status families experiencing immigration detention given the uncertainties inherent in immigration legal proceedings. This, we argue, could lead to new or renewed system avoidance behaviors.

During Fiscal Year 2015, ICE detained nearly 368,000 adult noncitizens (Transactional Records Access Clearinghouse 2016). Though the immigration detention and criminal incarceration systems can be characterized by similar physical environments with similarly punitive characteristics (Longazel et al. 2016; Patler, Sacha, and Branic 2019), several important distinctions remain. Most importantly, because immigration law violations are adjudicated under civil law and not criminal law, detention is not legally considered a sentence or a punishment, but rather an administrative holding process for noncitizens awaiting deportation. This civil law definition means detained individuals are unable to access many basic constitutional protections available to individuals experiencing other types of formal sanctioning. For instance, there are few constitutional limits on the length of detention; detained individuals who are subject to 
mandatory detention can be held indefinitely during the adjudication of their removal proceedings. A 2015 study by the Mexican government found that over 15 percent of Mexican nationals deported from the interior of the United States were detained for more than one year prior to deportation, and nearly half of those individuals were held for more than three years (Bermudez 2015). Importantly, and distinct from incarceration under criminal law (except in the case of pre-trial detention), the time spent in detention is not a sentence, but instead is legally considered an administrative holding process. However, the lack of clear constitutional protections generates substantial uncertainty in the process of immigration detention that can leave families vulnerable to collateral consequences for extended and indefinite periods of time (Hasselberg 2016, Golash-Boza 2019).

Another key feature of immigration detention, of course, is that it very often leads to deportation. To be sure, the possibility of permanent family separation can lead to fear and distress within immigrant families, even in the absence of detention (Dreby 2015; Enriquez 2015). Legal vulnerability can lead to a "spectrum of risk perceptions" and responses to that risk, even among documented immigrants (Asad 2020). However, it is likely these fears and risks are realized when a loved one is detained as the threat of deportation takes shape and becomes a tangible possibility. As Asad (2020) argues, it is precisely when immigrants are embedded in legal systems that they become aware of their potential visibility (or vulnerability) to other systems. In Asad's analysis, embeddedness can be due to being "on file" with the bureaucratic or punitive arms of the immigration system. Being exposed to those systems - perhaps especially the punitive arm — may lead to feelings of vulnerability surrounding — or avoidance of — other record-keeping bodies. As we will argue, this may be the case even among those who are not directly embedded —i.e. children and spouses. 
The consequences of this perceived vulnerability are likely numerous: throughout the process of parental immigration detention, spouses and children can experience prolonged periods of uncertainty and anticipatory stress (Pearlin and Bierman 2013) in which they experience distress related to what the future may hold for them. Because there are no constitutional limits on the length of detention, family members do not know if or when they will see their loved one again. Detained immigrants can be transferred between, or deported from, detention facilities, often in the middle of the night and with no notice, causing "psychological trauma...[to] family members [that] cannot be fully captured" (Human Rights Watch 2009: 79; see also Golash-Boza 2019). What is more, non-detained family members are virtually powerless in this situation: there is no legal mechanism by which children's experiences are considered as a legal basis for stopping a parent's deportation, except when the deportation would result in "exceptional and extremely unusual hardship" to the child (Thronson 2006). This uncertainty can lead to high levels of distress and severely infringe upon the family's ability to plan for the future (Chaudry 2011; Capps et al. 2015; Golash-Boza 2019). Furthermore, under immigration law, deportation is possible even when the individual has lived in the United States for long periods of time or committed minor crimes that, under criminal law, might not even result in jail time for U.S. citizens. As such, detained individuals and their families may express frustration, fear, or anger that the "punishment" does not fit the "crime" (Reiter and Coutin 2017; GolashBoza 2019; Patler 2018b), which could lead to additional efforts to avoid interactions with records-keeping institutions.

Family members may also suffer severe psychological and economic consequences when a loved one is detained. Gulbas et al. (2016) found that U.S. citizen children affected by parental deportation reported a greater burden of stressors in their lives - including financial struggles and 
stressed relationships with parents - which led to higher indications of depressive symptoms. Zayas et al. (2015) found that children whose parents have been detained or deported were more likely to experience attention deficits, anxiety disorders, depressive symptoms, and emotional disorders (see also Brabeck and $\mathrm{Xu} 2010$ ).

In summary, we advance the concept of compounded vulnerability as a mechanism to explain system avoidance behaviors in mixed-status families. Compound vulnerability is based in both the experience of parental/spousal confinement, but also in an individual's positionality as a member of a mixed- status family facing the possibility of long-term family separation via deportation. We argue that the deleterious impacts of parental incarceration combine with the uncertainty of the process of immigration detention (including, as we have described above, indefinite detention without sentence or certain end date, prolonged court experiences with few legal protections, all while experiencing tremendous uncertainty about case outcomes), and can lead children and non-detained spouses to avoid or further avoid interacting with surveilling institutions. As we will show, compounded vulnerability can impact all members of the family but can manifest in different types of system avoidance depending on a particular family member's structural positionality vis-à-vis their own legal status and the institutions they engage with regularly.

\section{METHODOLOGY}

We draw from 104 multigenerational and multi-perspective in-depth interviews with detained immigrants and their spouses/partners and children in 42 different families. The goal of this study was to understand the intergenerational collateral consequences of immigration 
detention. Figure 1 and Table 1 illustrate the breakdown of respondents. Consistent with overall patterns of detention and deportation, most detained parents were Latino males, while most spouses/partners were Latina women (Golash-Boza and Hondagneu-Sotelo 2013). 74 percent of respondents were transferred into ICE custody directly from a local law enforcement agency (31/42) and another 10 were apprehended later. While most detained parents were undocumented (70 percent), another 30 percent had some kind of legal status at the time of their apprehension by ICE. Spouses/partners were diverse in their legal status backgrounds: 49 percent were U.S. citizens (by birth or naturalization), 17 percent were documented non-citizens, and 34 percent were undocumented. In contrast, all but three of the children interviewed for the study were U.S. citizens. Most children were between 11 and 18 years old, but we interviewed children as old as 30 as necessary.

--Table 1 about here-

--Figure 1 about here--

Recruitment took place in several stages. The first group of interviewees included 42 detained parents. Each of these individuals had been held by ICE for six months or longer. Detained parents were interviewed in person while they were detained in four detention facilities in California. ${ }^{6}$ We then interviewed a current or former spouse/partner. These individuals were required to have had some sort of relationship or consistent communication with the detained parent before his/her detention in order to describe any changes in families' experiences that may have resulted from the detained parent's absence. Finally, when possible, we interviewed at least one child from each family. ${ }^{7}$

We employed separate instruments for the detained parent, spouse/partner, and child/youth interviews. The interview guides were built from existing studies of the educational, 
health, financial and other impacts of parental criminal incarceration and adapted to the immigration detention context. We aimed to capture multiple areas of life in order to gauge how families' experiences may have been impacted by parental detention. Our aim was to triangulate the child and parents' understandings of the parental detention experience. Detained parents responded to a structured questionnaire, adapted from the Boston Reentry Study (Western et al. 2015) that measured pre-detention experiences, legal history and immigration background, work experiences, and family background. Respondents answered a series of questions about each child for whom they were a biological parent or parental figure, including any challenges those children were facing during the detention process. The spouse/partner protocol covered a variety of topics regarding economic and housing stability, as well as impressions of the impacts of parental detention on each child. This protocol drew in part from the Boston Reentry Study Proxy Survey. Finally, the child instrument contained mostly original questions, but also drew on items from the year nine child follow-up wave of the Fragile Families and Child Wellbeing Study. Questions schemes were adjusted as necessary for older vs. younger children (e.g., whether or not respondents were in school, working, living at home). We conducted the interviews in English or Spanish, depending on the respondent's preference. The interviews ranged from forty minutes to over 2.5 hours for children, and between one to five hours for adults. Adults received a $\$ 40$ gift card and children received a $\$ 20$ gift card for their participation. Each family also received a resource packet with information about housing, legal, and food assistance programs.

After each interview, we wrote extensive field notes containing detailed ethnographic observations about the respondent and the interview, as well as a summary of the main themes that emerged during the interview. All interviews were audio recorded and transcribed. We then 
used Dedoose software to code and analyze the field notes and interview transcripts for each respondent. Broadly, we used flexible coding procedures, as outlined by Deterding and Waters (2018), to complete three rounds of coding. During the first wave, we created a set of open codes based on the literature on parental incarceration as well as the literature on families impacted by immigration law enforcement. As themes emerged from our first wave of coding, we created additional codes to capture these patterns. A final wave of selective coding allowed us to isolate specific instances of institutional attachment and system avoidance and mistrust. To ensure intercoder reliability, all transcripts were coded by at least two research team members and reviewed on a weekly basis.

\section{FINDINGS}

The purpose of our study was to uncover how and why immigration detention may impact the lives of children and spouses whose loved ones are apprehended and held in the custody of immigration authorities. Our findings provide evidence of spillover and intergenerational system avoidance and mistrust among spouses and children of detained individuals. Our results reveal that the compounded vulnerability of simultaneously experiencing the confinement of a loved one, while also being subject to the uncertainties of the immigration legal processes, can lead non-detained family members to exhibit system avoidance behaviors. That is, family members either began avoiding, further limited, or displayed weakened attachments to records-keeping institutions. However, these behaviors varied across children and adults due to the types of institutions they engage with on a regular basis. Consistent with the system avoidance literature, we find little change related to participation in church-based 
activities among spouses or children. In contrast to the system avoidance literature, we do not find evidence of avoidance of the labor market among family members.

\section{“Spillover” System Avoidance: Avoidance Behaviors Among Non-Detained Spouses}

We find that spousal immigration detention can lead non-detained spouses to engage in new or renewed system avoidance behaviors, especially in terms of their interactions with government-based records-keeping institutions. This behavior stemmed from compounded vulnerability consistent with spouses' legal and structural positionalities. On one hand, spouses, who often share precarious legal statuses with their detained partners, worried about their own possible detention or the re-detention of their partner after initial contact with immigration enforcement occurs. Even in cases where the non-detained spouses hold legal documentation or are U.S. citizens themselves, many still feared accessing services to which they and their children are entitled to (e.g., legal, medical, social services) due to fear of further exposing the family to immigration law enforcement.

One of the most common patterns of avoidance displayed by spouses was in relation to the criminal justice and legal systems. Regardless of their own legal status, many spouses reported adopting strategies to avoid interacting with the justice system to a greater degree than before their partner's apprehension. One common scenario was the avoidance of visitation programs. Although visitation can be an important contributor to family cohesion while a loved one is imprisoned (Bales and Mears 2008), many undocumented non-detained spouses made the difficult decision not to visit their husbands throughout the entire detention period due to fear of being detained themselves. Sofia, a 42-year-old spouse and mother of three, clearly expressed these concerns: "I was afraid to visit him because I thought they were going to ask me for my 
papers and I thought they would [arrest] me if they found out I didn't have any." Likewise, Azucena, a 33-year-old mother of four, stated:

In the eight months that my husband was detained, we never visited him. I felt scared because of my immigration status. I thought, 'what if they don't let me leave?' I also worried about my oldest son because he also doesn't have papers. I said to myself, 'it's not just going to be [just] me, it could also affect him.' It's very difficult.

For many families, these fears were externally validated. Throughout her husband Nicholas's two-year detention, Luciana a 37-year-old mother of four, was advised by Nicholas' attorney against interacting with the criminal justice system in any way, including via visitation. She recalled: "I would drive my children and their grandmother and I would wait in the parking lot while they went inside to visit." Many families felt that visitation was a sacrifice they had to make in order to avoid the possibility of losing yet another family member to the immigration enforcement system.

Legal system avoidance was also displayed by non-detained spouses who were not undocumented. Many spouses with more secure legal statuses (e.g., legal permanent residents, U.S. citizens) also reported increased fear of interacting with law enforcement officials that began after their spouse's experience with detention. Antonia, a 44-year-old legal permanent resident and mother of three, described the following incident:

I was driving once, and two cop cars pulled behind us and turned on their siren. I thought they were gonna [pull us over] and I freaked out...I completely blacked out. My husband [who had been released from detention after 24 months] was like, 'what's wrong?' And I 
just started crying...I completely [freaked out] because I felt...afraid...that they were going to pull me over.

Enduring familial separation had so deeply impacted Antonia that she become frightful of any encounter with law enforcement. "I don't owe them anything," she said, recognizing that she had not broken the law and was herself a lawful permanent resident, yet the mere thought of directly exposing herself and her husband to law enforcement terrified her. As a consequence of her husband's detention, Antonia adopted a hyperawareness of police and feared that any level of interaction with law enforcement would compromise her family's safety and unity.

Family members also developed new strategies to limit encounters with law enforcement in their daily routines. Fernanda, a 34-year-old mother of two, explained that her husband had become fearful of being out of the house following his release from detention on bond — and so had she: "he's afraid to be out in the street because of everything that has happened, and I'm much more at ease when I see that he's home from work and safe." She further described how the familial activities she and her husband previously enjoyed ceased after his detention due to fear of potential interactions with law enforcement: "It's not like before, we're much more afraid now. We don't really go out." Ariel, a 49 year-old father who was detained for seven months, revealed that even after his release on bond, he stopped going out with his family to do activities, for fear of running into law enforcement:

I'm kind of scared whenever I see the police. I only drive if I have to go to work. I'd rather stay home than be outside because...it's just...I don't feel safe anymore. I'd rather stay home ... It's not like before where I would say, let's go here, let's go there, let's go to the park, let's go to the movies. I don't feel comfortable with 
that anymore. That changed when I got out. I don't feel safe. That's how I feel now.

Spouses also avoided accessing much-needed public benefits, which can be critical resources for families experiencing such extensive financial disadvantage. In addition to losing a primary source of income due to detention, families accrue costs due to bonds, attorneys' fees, and other legal costs during detention. However, despite the financial burdens they face, many spouses made the difficult decision not to access public forms of financial support. Throughout her husband's two-year detention, 44-year-old mother of three Antonia decided not to seek reprieve from social programs such as Supplemental Nutrition Assistance Program (SNAP) or Temporary Assistance for Needy Families (TANF). She explained: “I don't [get food stamps or any government assistance]. It's just my income. And for the simple fact that I don't want them to hold that against us. I don't want [the government] to say 'instead of helping the country you're taking from it." Sentiments such as Antonia's were common; many families believed that applying for these programs could negatively impact their spouses' immigration case or potential future cases.

This same fear of exacerbating the detained spouse's case often bled into avoidance of other extremely dire necessities for families. Some families felt so concerned about negative interactions with law enforcement that they did not pursue even potentially life-saving services. Sofia was a cancer survivor and had been declared in remission prior to her husband Mateo's apprehension by ICE. However, during Mateo's time in detention, Sofia began to experience severe pains and expressed concern that her cancer may have returned. Sofia reluctantly revealed that she had decided not to go to the doctor due to fear that utilizing healthcare resources might somehow further expose her family's legal vulnerability to law enforcement. ${ }^{8}$ 
Importantly, however, most families in the study did not avoid labor market institutions - it was simply not an option for them not to work. In fact, many spouses and older children worked more during their loved ones' detention in order to make ends meet, though they often expressed concerns about perceived vulnerability to police during transportation to and from work. The families in our study who were regular participants in religious activities prior to detention also did not reduce their participation in such activities (outside of general concerns about being "out on the street" and therefore subject to potential run-ins with police), suggesting that individuals may not perceive religious institutions as records-keeping/surveilling institutions (Brayne 2014). For instance, Azucena kept her children enrolled in a free sports program at the local church so they would have continuity in their routine and "distract themselves" from the distress of their father's detention. The family also continued to receive other types of support from the church. Azucena's two oldest children, Carlos Jr. (age 14) and Jonathan (age 11), described going to the church's foodbank:

When it looked like we didn't have much to eat, there's food banks my mom took us to [at church]...They gave us bread, they gave us vegetables. Salads, milk, and meat. They had clothes too...We went for Christmas...they served us food...They had a Christmas dinner there and a movie... They would give us one free present.

Intergenerational System Avoidance and compounded vulnerability: Institutional Detachment of Children

Children of detained immigrants also expressed system avoidance behaviors rooted in their structural positionality and manifested in institutions in which they are most commonly embedded, including legal systems and schools. Regarding the former (legal systems), parental 
apprehension often exacerbated children's existing fears of deportation and permanent familial separation or led to new fears. As with their parents, some children developed strategies to avoid interacting with the legal system altogether. For example, fourteen-year-old Carlos Jr. described how his father's detention caused him to worry given his own undocumented status:

[While my dad was detained] I felt sort of insecure. As a matter of fact, some [ICE] officers were said to be roaming this area, knocking on people's door and arresting illegal immigrants...So our aunt informed us, and we decided we're going to look through the door [peephole] before opening it to make sure who's there.

Children expressed anticipatory stress that their parents could still be deported or, in the case of released immigrants, detained "at any moment." Smaller children were reported to cry inconsolably, wake with night terrors, and cling to their remaining parents. Children of all ages reported loss of appetite or over-eating, self-isolation, trouble sleeping or being unable to get out of bed, headaches, stomach pain, and dizziness. Lorena was detained for nearly two years (22 months). During her interview, Lorena's son, David, a 15 year-old with DACA status, sat next to her on the couch. As Lorena described her strategy of "always being ready" in case she was reapprehended, David grasped his mother's hands tightly and then buried his head in own his hands:

On the news, you see everything, they say that they [ICE]...can show up at any time for any little thing, by law...And this is what makes me [choking up]...I get up early and the first thing I do is take a shower and get dressed so I'm ready. I always carry my purse with everything in it. I have an envelope where I put everything...my birth certificate, my most important papers... No matter what happens, this has to be with me. 
David agreed, "It's living like I have to be prepared to leave at any second."

In addition to concern about law enforcement, children's most common changes of behavior occurred within the education system, the institution that is arguably most prevalentand most consequential — in their lives. A handful of teenagers and young adults, like Julian, dropped out of high school or college altogether, citing academic difficulties and emotional distress that emerged during a parent's confinement by immigration authorities and which persisted even after a parent's release on bond. In addition, nearly all children in the study reported attempts to avoid or reject resources (e.g., school counseling) and/or isolate themselves to avoid authority figures and even friends. These experiences were rooted in three key mechanisms embedded in their positionality as members of mixed-status families: fear of exposing family members in vulnerable legal statuses, concerns about stigmatization, and mistrust and cynicism in government institutions more broadly.

Children, most of whom were U.S. citizens, reported fear of school-based adults finding out about their families' challenging situations. Many children described concerns that talking to teachers about a parent's detention might somehow worsen the detained parents' case or even trigger the detention or deportation of other legally vulnerable family members. Eleven-year old Jonathan described his fear about his older brother, Carlos Jr.: "because he doesn't have papers. If he went [to detention], he wouldn't be able to come back and then it would [just] be me and my little brother and baby sister." Jonathan went on to describe that he learned how to fry an egg "just in case" his parents and older brother were deported, and he suddenly had to take on responsibility for his seven-year-old brother and infant sister. Jonathan therefore decided it was too risky to tell any adults outside of his family about what was happening. 
Like Jonathan, most children refrained from telling any adults at school about the parental detention. They worried that by discussing their parent's detention they might worsen their parent's case or place them or other family members at risk of apprehension. Carlos Jr. told us that he purposefully isolated himself from teachers and peers at his school. He described spending most of his recesses sitting alone at the edge of the soccer field, ignoring friends and teachers who approached him to ask what was wrong. He shared his desire to avoid being placed in the uncomfortable or potentially dangerous situation of having to talk about his father's detention. This was new behavior for Carlos, Jr., who himself is undocumented. While he reported being relatively open about his status to his teachers prior to his father's detention, now he was closed off and afraid of what repercussions might ensue.

Felipe, who was 16 years old and in high school at the time of his father's apprehension, also described purposefully avoiding school-based support around his father's detention because he was worried about exacerbating the family's current legal troubles. He recalled:

I didn't want [to cause] a problem. I didn't trust [my teachers] and I was afraid of what [they would do]. Are they gonna talk to me one-on-one or are they gonna make me talk with a counselor or someone I don't know? I didn't want any problems. I was a little bit worried. What are they gonna think? What are they gonna say?

Felipe described how the uncertainty of his teachers' reactions prevented him from seeking them out as a source of social and emotional support. He mentioned that "therapy for students" was available, but said, "it was [offered through] the school, so I didn't trust it. The reason I didn't tell them is because I thought in my mind, 'is my mom gonna be okay...is she not?'” (emphasis added). Felipe worried about exposing the family's secret about his father's detention and he also feared that sharing this personal piece of information might expose the family to further legal 
troubles. These examples highlight how some children come to perceive schools as places that could either exacerbate or worsen their family's situation of both imprisonment and legal vulnerability, rather than as spaces where they can receive support.

Other children described schools as places where they could be stigmatized by teachers or peers because of their parent's detention. Jonathan described worry that a teacher might tease him or stand him up in the front of the class and "tell everyone" what was happening to himsomething his first grade teacher had done a few years before when Jonathan had contracted head lice. Other children worried about negative interactions with friends. Daisy, 11 years old, from Los Angeles, explained that students are sometimes bullied at school for "little things" and she feared that if other students found out about her father's detention she might also become a victim of bullying. Twenty year-old Cassandra also worried about stigma — specifically that her father might be deemed a "felon" by others and that she herself might be ostracized for it.

Even when children knew about other kids whose parents had been incarcerated under criminal law, they feared that the added layer of detainment by immigration authorities would be cause for peer ridicule. Jonathan, 11 years old, told us that he had a friend whose father had been in jail, but he didn't talk to that friend about his own father because, "my situation is very different." In cases where peers found out about parental immigration detention, children would try to justify it. Twenty-seven-year-old Andres recalled, "I told my friends that my dad's in jail, but it's not because he's a bad person, it is because he's an immigrant, he got deported, and came back." For Andres, it was critical to try to justify his father's detention for lacking legal status and differentiate it from criminal incarceration for committing a criminal act.

Many children also reported that their parents' detention had led them to feel extensive mistrust in the legal system, which discouraged them from wanting to participate in that system. 
Natalia was 17 when her stepfather, Angel, was detained. Angel had been at work when ICE agents showed up with an arrest warrant for his co-worker; when Angel couldn't prove legal residency, they arrested him as well. Natalia described how the indefinite nature of his detention made her stop trusting the immigration legal system altogether: "I stopped trusting... I felt like [the process] took so long, honestly, that's when I started being like, aw man, they're just idiots, they're racist idiots. I started being more judgmental.” The seemingly spontaneous arrests, coupled with the uncertainties of the immigration legal process, left many families in disarray and negatively influenced children's perceptions of, and trust in, the justice system.

Other child respondents expressed feelings of frustration that their voices were not heard in the legal process. Ximena's father was detained when she was 21 years old and she then became the primary caregiver for her three siblings - the youngest of whom was nine at the time. Ximena described character letters she and her siblings wrote to the immigration judge to endorse her father's claim to stay in the United States:

I even wrote in detail what was going on with my youngest brother, and it just did not seem like they cared. I believe the judge made a comment at one point, saying that basically we're all adults and that we can care for ourselves. For myself, yeah that's fine. But my younger brother had all these problems with school, he dropped out, and he's been diagnosed with a mood disorder...but they just didn't care about that. However, while some children stated firmly that they stopped trusting the criminal justice and immigration systems, others expressed a desire to change the system from within — suggesting the desire for further engagement with the system. When asked about their future career goals, several children mentioned hoping to pursue a career in law enforcement, criminal justice or the immigration system itself, as a way to make sure no other children would have to suffer as they 
have. For example, 13-year old Julieta explained how her father's detention motivated her to become an immigration lawyer:

Interviewer: What made you want to [be a lawyer]?

Julieta: Um...because back then what I used to go through. Like when I was little. I was only eight when I lost my house and everything happened and so every time I'll visit [my dad] in the [detention facility], facing the window, not being able to hug or anything... it kind of made me be like, if this is what I'm going through maybe — who knows—I could do this later on in life...[help] people who are in the situation like me.”

\section{DISCUSSION}

While immigration detention is not a new phenomenon, the rate at which noncitizens are apprehended in the interior of the United Sates, held in detention, and at risk of deportation has increased significantly in recent years and requires deep and sustained investigation. Although scholarship on the consequences of immigration enforcement continues to develop, few studies have examined the experiences of immigrants and their families as they go through the process of contact with the immigration system. Our research provides an analysis of some of the experiences mixed-status families undergo when a loved one is confined in immigration detention facilities for long periods of time. We draw parallels between the spillover and intergenerational collateral consequences of incarceration while also distinguishing the unique features of the immigration legal system and of mixed status families' behaviors while experiencing that system. We advance the concept of compounded vulnerability to 
describe the simultaneous experience of parental incarceration combined with the uncertainty of immigration legal processes that can result in permanent family separation via deportation.

Our project generates at least four contributions to the literatures on system avoidance, immigrant families, and parental incarceration. First, our research seeks to begin to answer two important questions raised in existing research on system avoidance (e.g. Brayne 2014; Haskins and Jacobsen 2017): (1) does the behavior spill over onto family members and, (2) if so, what are the mechanisms behind that behavior. Our findings provide some evidence of spillover system avoidance onto spouses, regardless of their own legal status and protections. We also offer evidence of disengagement from institutions among children. For some families, these sentiments and actions are new and for others they are enhanced. We find that spouses of detained individuals begin to avoid — or further avoid—interactions with law enforcement officials and institutions, as well as with much needed public services during and after the detention period. Some children also begin to express mistrust of the law and legal authorities more generally. Such behaviors can lead to social isolation and lack of access to support.

Second, our findings underscore several mechanisms behind this spillover and intergenerational system avoidance behavior among spouses and children. Many spouses and children fear the apprehension of non-detained family members in vulnerable legal statuses. They also express concerns that involvement in formal records-keeping institutions will damage the family's uncertain legal future. For children, concerns about stigmatization surrounding their mixed-status families' vulnerable legal status also play into decisions to avoid seeking schoolbased help and support. Our findings therefore indicate that policies aimed at noncitizens may have short- and long-lasting downstream consequences for families' institutional attachment and trust in the law and legal authorities. The system embeddedness (Asad 2020) of a loved one 
appears to impact not just the individual who has directly had contact with the justice system, but can also lead his/her family members to avoid, or attenuate their attachment to, institutions.

Third, and relatedly, this study helps to bridge two bodies of literature that have developed in relative isolation from one another - the literature on chilling effects of immigration enforcement and the literature on system avoidance-yet describe a very similar phenomenon: avoidance and mistrust among legally vulnerable populations. Our results provide additional evidence of the chilling effects of ramped up immigration law enforcement that can lead immigrants and their families to avoid or mistrust government institutions tasked with providing necessary services to this population (Nuñez \& Heyman 2007; Menjívar and Abrego 2012; Jefferies 2014; Patler 2018a). This is the case even when individuals are U.S. citizens and therefore not directly vulnerable to deportation (Watson 2014; Pedraza, Cruz Nichols and LeBrón 2017; Cruz Nichols, LeBrón and Pedraza 2018).

Fourth, while there is significant evidence of the spillover impacts of incarceration under criminal law, there is far less research on the children and spouses/partners of individuals detained by immigration authorities (for exceptions, see Brabeck and Xu 2010, Zayas et al. 2015, Golash-Boza 2019). Our findings suggest that having a family member detained by immigration authorities may generate similar disadvantages to those faced by citizen families experiencing the incarceration under criminal law (Foster and Hagan 2007; Arditti 2012; Haskins et al. 2018). However, as our concept of compounded vulnerability suggests, the lives of mixed-status family members may be additionally interrupted by uncertainty about the future and the possibility of permanent family separation.

Our study therefore places under theoretical and empirical scrutiny the legal premise that immigration detention is a non-punitive administrative process. Although immigration detention 
centers resemble jails in their characteristics and operation, immigration law is administrative and therefore legally construed as a non-punitive administrative mechanism. As a result, detained immigrants lack many of the constitutional protections available under criminal law, including the right to a court-appointed attorney or constitutional protections against indefinite detention. Our study exposes that these impacts spill over onto the spouses and children of detained individuals and lead to compounded vulnerability.

Future research could help establish the generalizability of our findings. Although the Department of Homeland Security does not regularly release information about the individuals it detains, researchers should strive to study immigration detention in ways that could help develop population estimates of the collateral consequences of this system. Comparative research that can explore variation in children's and parents' demographic backgrounds would also be helpful. For example, the majority of detained parents in our study were Latino-identified fathers, which leaves underexplored ethnic and gender differences on the effects of parental/spousal detention. Future research could also explore the idea of compounded vulnerability in geographic settings outside California which may represent a different immigration law enforcement context. Additional in-depth and longitudinal research should also focus on the long-term outcomes of spillover and intergenerational system avoidance, and whether these outcomes change as parents/spouses are detained, deported and/or released. Doing so could uncover whether, how, and to what extent immigration detention is linked to inequality in immigrant communities across the United States.

Our findings underscore how immigration policy can produce and exacerbate inequalities for an expanding group of already disadvantaged individuals. This research may be especially useful for educators concerned with how to best serve vulnerable students or local governments 
who want to better serve mixed-status families. While our research was able to uncover some troubling reports of disengagement from institutional resources, it was — by design — limited to the expressions of family members of detained individuals. Future research that can further explore institutional actors (such as teachers' and school districts') responses to immigration law enforcement will be a highly relevant and necessary addition to the present study. Finally, and

relatedly, our analyses reveal the seemingly ubiquitous presence of fear and negative emotions in the lives of mixed-status families whose loved ones are detained. Given the close links between psychological wellbeing, mobility, and even morbidity, future work on the short- and long-term repercussions of fear and other negative emotions is greatly needed, especially in the present context of increasing anti-immigrant actions and sentiment.

\section{CONCLUSION}

These findings may be particularly relevant for understanding the experiences of mixedstatus families in the current policy context. The use of immigration detention has skyrocketed in recent decades and is poised to continue expanding (Golash-Boza and Hondagneu-Sotelo 2013; Patler and Golash-Boza 2017). While changes to U.S. immigration laws since 1996 have vastly expanded the categories of removable offenses and the use of mandatory and indefinite detention, Executive Orders signed in 2017 focused on the enforcement of these laws by prioritizing the apprehension not only of noncitizens convicted of crimes, but of those charged with offenses (regardless of conviction), as well as those suspected of committing a chargeable offense, and any and all undocumented immigrants (The White House Office of the Press Secretary 2017). The average daily detained population in the U.S. $-55,000$ as of summer 
2019-is currently at an historic high. ${ }^{9}$ An August 2019 ICE raid on a poultry factory in Mississippi resulted in 680 apprehensions - the most in any one raid in the past decade - makes clear that the Trump administration intends to fulfill its promises. We are therefore likely to witness a dramatic upsurge of individuals at varying stages within the process of criminal incarceration, immigration detention, and deportation or release. As such, our findings may be timely and relevant for understanding the links between enforcement, inequality, and community wellbeing more broadly. 


\section{REFERENCES}

Arditti, Joyce A. 2012. Parental Incarceration and the Family: Psychological and Social Effects of Imprisonment on Children, Parents, and Caregivers. New York, NY: New York University Press.

Asad, Asad L. 2020. “On the Radar: System Embeddedness and Latin American Immigrants' Perceived Risk of Deportation.” Law and Society Review 54(1):133-167.

Bales, William D. and Mears, Daniel P. 2008. "Inmate Social Ties and the Transition to Society: Does Visitation Reduce Recidivism?" Journal of Research in Crime and Delinquency. 45: 287-321.

Bermudez, Juan. 2015. “The Impact of US Immigration Policy in Deported Mexicans Based on the Survey on Migration in the Northern Border of Mexico (EMIF Norte).” Pp. 1-25: Consejo Nacional de Población, México.

Boswell, Gwyneth, and Peter Wedge. 2002. Imprisoned Fathers and Their Children. London: UK: Jessica Kingsley Publishers.

Brabeck, Kalina and Qingwen Xu. 2010. “The Impact of Detention and Deportation on Latino Immigrant Children and Families: A Quantitative Exploration." Hispanic Journal of Behavioral Sciences 32(3):341-361.

Brayne, Sarah. 2014. "Surveillance and System Avoidance: Criminal Justice Contact and Institutional Attachment." American Sociological Review 79(3):367-391.

Capps, Randy, Heather Koball, Andrea Campetella, Krista Perreira, Sarah Hooker and Juan Manuel Pedroza. 2015. "Implications of Immigration Enforcement Activities for the Well-Being of Children in Immigrant Families: A Review of the Literature." Washington, D.C.: Urban Institute and Migration Policy Institute

Chaudry, Ajay. 2011. "Children in the Aftermath of Immigration Enforcement." The Journal of the History of Childhood and Youth 4(1): 137-154.

Chaudry, Ajay, Randolph Capps, Juan Manuel Pedroza, Rosa Maria Castañeda, Robert Santos and Molly M. Scott. 2010. "Facing Our Future: Children in the Aftermath of Immigration Enforcement." 4(1): 137-154. Washington, D.C.: The Urban Institute.

Cruz Nichols, Vanessa, Alana MW LeBrón, and Francisco I. Pedraza. 2018. "Spillover Effects: Immigrant Policing and Government Skepticism in Matters of Health for Latinos." Public Administration Review 78(3): 432-443.

Dallaire, Danielle H., Anne Ciccone, and Laura C. Wilson. 2010. “Teachers' Experiences with and Expectations of Children with Incarcerated Parents." Journal of Applied Developmental Psychology 31(4): 281-290. 
Deterding, Nicole M., and Mary C. Waters. 2018. "Flexible Coding of In-depth Interviews: A Twenty-first-century Approach." Sociological Methods \& Research: 0049124118799377.

Dreby, Joanna. 2015. Everyday Illegal: When Policies Undermine Immigrant Families. Berkeley and Los Angeles, CA: University of California Press.

Enriquez, Laura E. 2015. "Multigenerational Punishment: Shared Experiences of Undocumented Immigration Status within Mixed-Status Families." Journal of Marriage and Family 77(4)939-53.

Foster, Holly, and John Hagan. 2007. "Incarceration and Intergenerational Social Exclusion." Social Problems 54:399-433.

Foster, Holly, and John Hagan. 2015. "Maternal and Paternal Imprisonment and Children's Social Exclusion in Young Adulthood." Journal of Criminal Law \& Criminology 105(2): 387.

Goffman, Alice. 2009. "On the Run: Wanted Men in a Philadelphia Ghetto." American Sociological Review 74(3):339-357.

Golash-Boza, Tanya. 2019. Punishment Beyond the Deportee: The Collateral Consequences of Deportation. American Behavioral Scientist 1-19

Golash-Boza, Tanya and Pierrette Hondagneu-Sotelo. 2013. "Latino Immigrant Men and the Deportation Crisis: A Gendered Racial Removal Program.” Latino Studies 11(3):271-92.

Gulbas, Lauren E., Luis H. Zayas, Hyunwoo Yoon, Hannah Szlyk, Sergio Aguilar-Gaxiola, and Guillermina Natera. 2016. "A Mixed-method Study Exploring Depression in US Citizenchildren in Mexican Immigrant Families." Child: Care, Health and Development 42(2): 220-230.

Hagan, John, and Holly Foster. 2012. "Children of the American Prison Generation: Student and School Spillover Effects of Incarcerating Mothers.” Law \& Society Review 46(1):37-69.

Haskins, Anna R. 2014. "Unintended Consequences: Effects of Paternal Incarceration on Child School Readiness and Later Special Education Placement." Sociological Science 1: 141158.

Haskins, Anna R., and Wade C. Jacobsen. 2017. "Schools as Surveilling Institutions? Paternal Incarceration, System Avoidance, and Parental Involvement in Schooling." American Sociological Review 82(4): 657-684.

Haskins, Anna R., Mariana Amorim, and Meaghan Mingo. 2018. "Parental Incarceration and Child Outcomes: Those at Risk, Evidence of Impacts, Methodological Insights, and Areas of Future Work." Sociology Compass 12(3):1-14. 
Hasselberg, Ines. 2016. Enduring Uncertainty. Deportation, Punishment and Everyday Life. Vol. 17. New York, NY: Berghahn Books, 2016.

Human Rights Watch. 2009. "Locked up Far Away. The Transfer of Immigrants to Remote Detention Centers in the United States.” Retrieved Oct. 24, 2018. https://www.hrw.org/report/2009/12/02/locked-far-away/transfer-immigrants-remotedetention-centers-united-states

Jefferies, Julian. 2014. "The Production of "Illegal" Subjects in Massachusetts and High School Enrollment for Undocumented Youth.” Latino Studies 12(1):65-87.

Longazel, Jamie, Jake Berman and Benjamin Fleury-Steiner. 2016. "The Pains of Immigrant Imprisonment." Sociology Compass 10(11):989-98.

Menjívar, Cecilia and Leisy J. Abrego. 2012. "Legal Violence: Immigration Law and the Lives of Central American Immigrants." American Journal of Sociology 117(5):1380-421.

Nuñez, Guillermina Gina and Josiah McC. Heyman. 2007. "Entrapment Processes and Immigrant Communities in a Time of Heightened Border Vigilance." Human Organization 66(4):354-65.

Patler, Caitlin and Tanya Golash-Boza. 2017. "The Fiscal and Human Costs of Immigrant Detention and Deportation in the United States"." Sociology Compass 11(11):1-9.

Patler, Caitlin. 2018a. "To Reveal or Conceal: How Diverse Undocumented Youth Navigate Legal Status Disclosure." Sociological Perspectives 61(6):857-73.

Patler, Caitlin. 2018b. "Citizens but for Papers: Undocumented Youth Organizations, AntiDeportation Campaigns, and the Boundaries of Belonging." Social Problems 65(1):95115.

Patler, Caitlin and Nicholas Branic. 2017. "Patterns of Family Visitation During Immigration Detention.” The Russell Sage Foundation Journal of the Social Sciences 3(4):18-36.

Patler, Caitlin, Jeffrey O. Sacha and Nicholas Branic. 2019. "The Black Box within a Black Box: Solitary Confinement Practices in a Subset of U.S. Immigrant Detention Facilities." Journal of Population Research 35(4):435-65.

Pearlin, Leonard I., and Alex Bierman. 2013. "Current Issues and Future Directions in Research into the Stress Process." In Handbook of the Sociology of Mental Health. Springer, Dordrecht. 325-340.

Pedraza, Francisco, Vanessa Cruz Nichols and Alana LeBrón. 2017. "Cautious Citizenship: The Deterring Effect of Immigration Issue Salience on Health Care Use and Bureaucratic 
Interactions among Latino Us Citizens." Journal of Health Politics, Policy and Law 42(5):925-60.

Reiter, Keramet, and Susan Bibler Coutin. 2017. "Crossing Borders and Criminalizing Identity: The Disintegrated Subjects of Administrative Sanctions." Law \& Society Review 51(3): $567-601$.

The Marshall Project. 2018. "When Your Dad Gets Locked Up-And Then Deported." Retrieved Oct. 24, 2018. https://www.themarshallproject.org/2018/05/10/when-your-dadgets-locked-up-and-then-deported

The White House Office of the Press Secretary. 2017. "Executive Order: Enhancing Public Safety in the Interior of the United States." Washington, D.C.

Thronson, David B. "Choiceless Choices: Deportation and the Parent-child Relationship." Nevada Law Journal 6 (2006): 1165.

Transactional Records Access Clearinghouse. 2016. "New Data on 637 Detention Facilities Used by ICE in FY 2015.” Retrieved October 24, 2018 (http://trac.syr.edu/immigration/reports/422/\#fl).

Travis, Jeremy, Bruce Western, and F. Stevens Redburn. 2014. "The Growth of Incarceration in the United States: Exploring Causes and Consequences." The National Academies Press Washington, D.C.

Turney, Kristin. 2014. "Stress Proliferation across Generations? Examining the Relationship between Parental Incarceration and Childhood Health." Journal of Health and Social Behavior 55(3):302-19.

Turney, Kristin and Anna Haskins. 2014. "Falling Behind? Children's Early Grade Retention after Paternal Incarceration." Sociology of Education 87(4):241-58.

Turney, Kristin. 2015. "Paternal Incarceration and Children's Food Insecurity: A Consideration of Variation and Mechanisms." Social Service Review 89(2), 335-367.

Wakefield, Sara and Christopher Wildeman. 2013. Children of the Prison Boom: Mass Incarceration and the Future of American Inequality. Oxford: Oxford University Press.

Watson, Tara. 2014. "Inside the Refrigerator: Immigration Enforcement and Chilling Effects in Medicaid Participation.” American Economic Journal: Economic Policy 6(3):313-38.

Western, Bruce, Anthony A. Braga, Jaclyn Davis and Catherine Sirois. 2015. "Stress and Hardship after Prison.” American Journal of Sociology 120(5):1512-47.

Wildeman, Cristopher. 2014. "Parental Incarceration, Child Homelessness, and the Invisible 
Consequences of Mass Imprisonment." The Annals of the American Academy of Political and Social Science 651(1): 74-96. https://doi.org/10.1177/ 0002716213502921.

Wildeman, Cristopher, Hedwig Lee, \& Megan Comfort. 2013. "A New Vulnerable Population? The Health of Female Partners of Men Recently Released from Prison." Women's Health Issues 23(6): 335-340.

Wildeman, Christopher, and Kristin Turney. 2014. "Positive, Negative, or Null? The Effects of Maternal Incarceration on Children's Behavioral Problems." Demography 51(3): 10411068.

Zayas, Luis H., Sergio Aguilar-Gaxiola, Hyunwoo Yoon, and Guillermina Natera Rey. 2015. "The Distress of Citizen-children with Detained and Deported Parents." Journal of Child and Family Studies 24(11): 3213-3223. 


\section{NOTES}

${ }^{1}$ Mixed-status households include at least one family member at risk of detention or deportation.

${ }^{2}$ Advocacy groups and journalists have focused on this topic; see for example the Marshall Project 2018; Chaudry et al. 2010.

${ }^{3}$ In 2019 , the average daily detained population has jumped to a record high of 55,000 individuals per day. In a 5-4 decision in Jennings v. Rodriguez in February 2018, the Supreme Court held in Jennings v. Rodriguez that detained immigrants do not need to receive periodic bond hearings, thus allowing for indefinite detention. In March 2019, the Supreme Court ruled in Nielsen v. Preap that the government may mandatorily and indefinitely detain any immigrant with a criminal record at any time after they have been released from imprisonment.

${ }^{4}$ We note that migration scholars have not used the term "system avoidance" to describe a similar phenomenon, likely due to disciplinary norms.

${ }^{5}$ This level of hardship can usually be demonstrated only due to a child's extremely illness or physical disability, and even that option is disallowed when the child is not a U.S. citizen or the parent has been convicted of certain categories of crimes.

${ }^{6}$ Detainees were initially recruited as part of a larger survey of class members of Rodriguez $v$. Robbins, class action litigation mandating bond hearings for most detainees held in the Central 
District of California for more than 180 days. The four facilities where they were housed represent the universe of facilities holding Rodriguez class members during the study.

${ }^{7}$ Not all family units included a spouse/partner or children who were eligible to participate. For example, in some cases the children were too young and therefore fell outside of our sampling criteria.

${ }^{8}$ In this case, the researchers helped link Sofia with a non-profit clinic that provides free or lowcost oncology services regardless of legal status.

${ }^{9}$ See: https://psmag.com/news/ice-is-detaining-more-people-than-ever-and-for-longer (accessed August 19, 2019) 
TABLES \& FIGURES

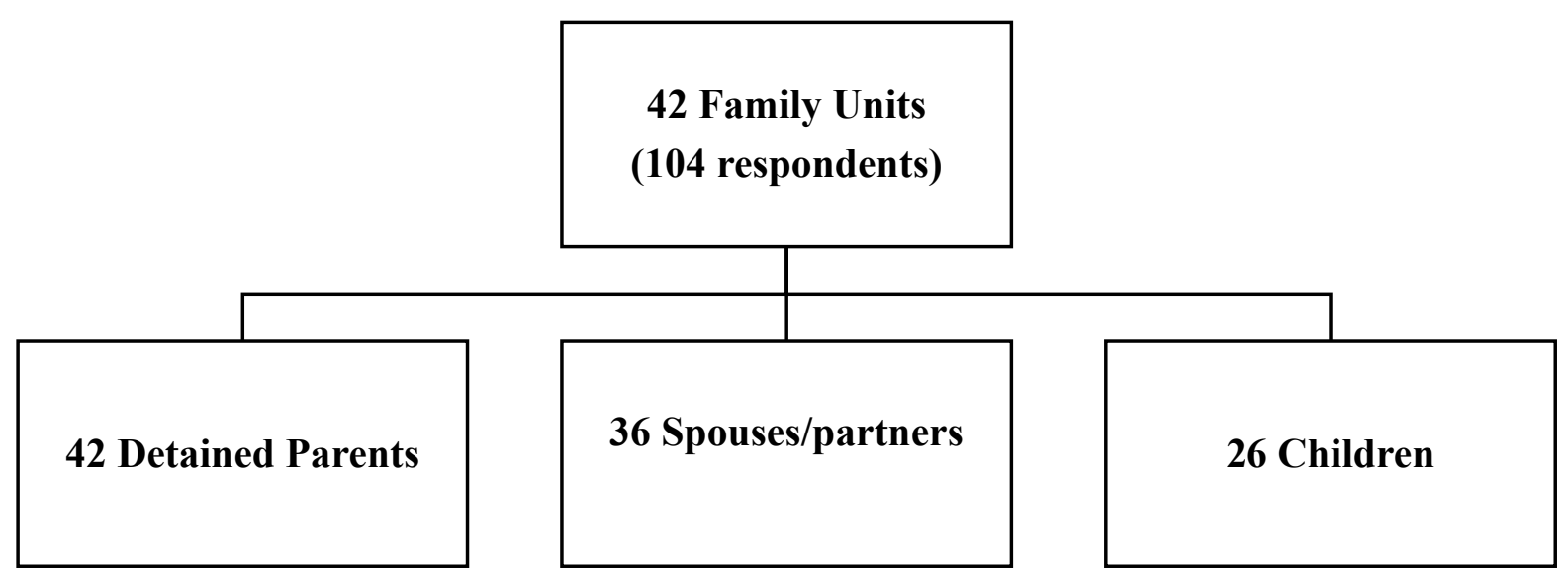

Figure 1. Respondent Breakdown

Table 1. Respondent Characteristics

\begin{tabular}{|c|c|c|c|}
\hline & $\frac{\text { Detained }}{\underline{\text { Parent }}}$ & $\frac{\frac{\text { Non- }}{\text { detained }}}{\text { Parent }}$ & Child \\
\hline \multicolumn{4}{|l|}{ Gender } \\
\hline Male & 0.93 & 0.11 & 0.46 \\
\hline Female & 0.08 & 0.89 & 0.54 \\
\hline $\begin{array}{l}\text { Transferred from local Law } \\
\text { enforcement }\end{array}$ & 0.74 & N/A & $\mathrm{N} / \mathrm{A}$ \\
\hline \multicolumn{4}{|l|}{ Legal status } \\
\hline US citizen & - & 0.49 & 0.88 \\
\hline Documented non-citizen & 0.3 & 0.17 & 0.08 \\
\hline Undocumented & 0.7 & 0.34 & 0.04 \\
\hline Age (range) & $41(20-69)$ & $42(20-64)$ & $19(11-34)$ \\
\hline \multicolumn{4}{|l|}{ Self-reported ethnicity } \\
\hline Hispanic/Latina/o & 0.89 & 0.75 & 0.96 \\
\hline Other & 0.11 & 0.25 & 0.04 \\
\hline $\mathrm{N}$ & 42 & 36 & 26 \\
\hline
\end{tabular}

Note: Not all values add to 1 due to rounding. 